\title{
PENGARUH MINAT BACA DAN PERAN DOSEN PEMBIMBING TERHADAP KEBERHASILAN PENULISAN TUGAS AKHIR
}

\author{
BAHRUDI EFENDI DAMANIK \\ Manajemen Informatika, AMIK-STIKOM Tunas Bangsa Pematangsiantar \\ E-mail: bahrudiefendi@gmail.com
}

\begin{abstract}
:
The purpose of the study is to examine whether there is an influence of reading interest and the role of supervisors partially or simultaneously on the success of writing the final assignment. The research was conducted at AMIK Tunas Bangsa Pematangsiantar by taking a sample of 78 people from 369 population populations using calculations using Slovin formula. The method used is the survey method and data collection carried out through observation, interviews, and distributing questionnaires using a Likert scale as a measuring device. The sampling technique using purposive sampling is a sampling technique of data sources with certain considerations, the analytical technique used is multiple lenier analysis techniques. In analyzing the data used several descriptive analysis techniques to determine the distribution of respondents' answers to the overall concept being measured, quantitative analysis using numbers and calculations with statistical methods. The results of the analysis show that partial reading interest has a positive and significant effect on the success of the final assignment, tcount $>t$ table (3.167> 1.991), the role of partial supervisor is positive and significant effect on the success of the final assignment, tcount> $t$ table (2.915> 1.991), reading interest and the role of supervisors simultaneously have a positive and significant effect on the success of the final assignment where the value of Fcount > Ftable is $(20,094>3,12)$.
\end{abstract}

Keywords: Reading Interest, Supervisor, Final Project

\section{PENDAHULUAN}

K arya ilmiah adalah suatu karya penulisan dari suatu penelitian yang harus memenuhi minimal tiga ciri utama keilmuan yaitu, rasional, empiris, dan sistematis. Rasional artinya kegiatan penelitian ini dilakukan dengan caracara yang masuk akal sehingga terjangkau oleh penalaran manusia. Empiris artinya cara-cara yang digunakan dalam penelitian itu dapat diamati oleh indra manusia, sehingga orang lain dapat mengamati dan mengetahui cara-cara yang akan digunakan. Dan sistematis artinya proses yang digunakan dalam penelitian ini menggunakan langkah-langkah tertentu yang bersifat logis.

Tugas Akhir adalah merupakan karya ilmiah yang diwajibkan kepada mahasiswa tingkat akhir sebagai syarat kelulusan. Untuk memulai penulisan Tugas Akhir dibutuhkan suatu konsep yang jelas tentang apa yang menjadi permasalahan pokok yang akan dituliskan. Dari amatan penulis yang juga merupakan salah seorang Dosen, dan juga kebetulan ditugaskan sebagai Dosen Pembimbing Tugas Akhir, ada beberapa masalah elementer yang dihadapi oleh mahasiswa dalam merancang, menyusun, dan menyelesaikan tugas akhir mereka. Hal tersebut antara lain mahasiswa mengalami kesulitan untuk menentukan judul dari tugas akhirnya. Dalam merangkai kata-kata menjadi suatu paragraf dalam penulisan juga menjadi 
sesuatu yang begitu berat bagi mereka. Berikutnya dalam menentukan permasalahan utama yang akan dibahas dalam penelitian.

Keberhasilan penulisan Tugas Akhir oleh mahasiswa tentunya dipengaruhi oleh banyak faktor, antara lain yang akan penulis teliti adalah masalah minat baca dan Dosen Pembimbing. Minat baca yang rendah merupakan masalah klasik yang dihadapi oleh sebagian besar anak didik di lembaga-lembaga pendidikan yang ada di Indonesia, juga terjadi di AMIK Tunas Bangsa. Kurang tertariknya mahasiswa memanfaatkan waktunya untuk membaca bisa dilihat dari kosongnya perpustakaan yang sudah ada pada jam-jam di luar jam kuliah, dan juga ketergantungan mahasiswa pada modul maupun materi ajar yang disiapkan oleh dosen.

Pada penelitian sebelumnya yang dilakukan oleh Siagian (2013) ada pengaruh positif minat dan kebiasaan belajar siswa secara bersama-sama terhadap prestasi belajar matematika sedangkan Achroza (2013) pada penelitian lainnya menyatakan hubungan negatif yang sangat signifikan antara komunikasi interpersonal dosen pembimbing mahasiswa, dan problem focused coping dengan stres dalam menyusun skripsi pada mahasiswa.

Berbeda dengan penelitian sebelumnya, pada kali ini penulis ingin mengkombinasikan variabel bebas pada penelitian terdahulu sekaligus yaitu minat baca dan peran dosen pembimbing yang penulis anggap dari amatan selama ini menjadi variablel yang paling berpengaruh terhadap keberhasilan penulisan tugas akhir.

Berdasarkan latar belakang masalah diatas, maka penulis merumuskan beberapa masalah (asosiatif) yaitu:

1. Bagaimana pengaruh minat baca terhadap keberhasilan penulisan tugas akhir?

2. Bagaimana pengaruh peran dosen pembimbing terhadap keberhasilan penulisan tugas akhir?

3. Bagaimana pengaruh minat baca, dan peran dosen pembimbing terhadap keberhasilan penulisan tugas akhir?

\section{TINJAUAN TEORETIS}

\section{Minat Baca}

Membaca adalah hal yang sangat penting dalam memajukan setiap pribadi manusia maupun suatu bangsa. Dengan membaca, kita dapat memperluas wawasan dan mengetahui dunia. Namun sebuah persoalan membaca yang selalu mengemuka, terutama di kalangan pelajar/mahasiswa, adalah bagaimana cara menimbulkan minat dan kebiasaan membaca. Banyak negara berkembang memiliki persoalan yang sama, yaitu kurangnya minat membaca di kalangan masyarakatnya.

Menurut (Herdianto, 2011), membaca buku merupakan salah satu aktivitas belajar yang efektif untuk mendapatkan ilmu dan pengetahuan. Dengan membaca mahasiswa ataupun dosen dapat memperoleh pengetahuan dengan cepat dan mudah karena tinggal memilih buku yang akan dibaca, membukanya dan mulai membaca kata-perkata. Oleh karena itulah membaca semestinya menjadi aktivitas 
pokok civitas akademika khususnya mahasiswa. Mahasiswa adalah salah satu komponen civitas akademik yang sedang menuntut ilmu pengetahuan, maka dari itu membaca semestinya menjadi agenda pokok mahasiswa. Dengan membaca akan menjadikan sumber inspirasi, sumber pengetahun dan mengasah kekritisan mahasiswa.

Rahim yang dikutip Failasuf (2013: 28), mengemukakan bahwa minat baca ialah keinginan yang kuat disertai usaha seseorang untuk membaca. Seseorang yang mempunyai minat membaca yang kuat akan diwujudkannya dalam kesediaannya untuk mendapat bahan bacaan dan kemudian membacanya atas kesadaran sendiri atau dorongan dari luar.

Menurut Wahadaniah yang dikutip Indarwati (2011: 29), minat baca adalah suatu perhatian yang kuat dan mendalam disertai dengan perasaan senang terhadap kegiatan membaca sehingga dapat mengarahkan seseorang untuk membaca dengan kemauannya sendiri atau dorongan dari luar. Minat membaca juga merupakan perasaan senang seseorang terhadap bacaan karena adanya pemikiran bahwa dengan membaca itu dapat diperoleh kemanfaatan bagi dirinya. Minat baca adalah suatu kecenderungan kepemilikan keinginan atau ketertarikan yang kuat dan disertai usaha-usaha pada diri seseorang terhadap kegiatan membaca yang dilakukan secara terus-menerus dan diikuti dengan rasa senang tanpa paksaan, atas keinginannya sendiri atau dorongan dari luar, sehingga seseorang tersebut mengerti atau memahami yang dibacanya.

Berdasarkan pendapat-pendapat diatas maka peneliti mengambil kesimpulan bahwa minat baca adalah hasrat yang kuat datang dari diri seseorang untuk membaca bacaan yang dilakukan dengan senang hati tanpa paksaan dari orang lain yang akibat dari aksi membacanya dapat berpengaruh positif dengan bertambahnya pengetahuan baru dari pembaca itu sendiri.

\section{Dosen Pembimbing}

Pembimbing yang baik adalah pembimbing yang mampu mengeksplorasi potensi mahasiwa yang dibimbingnya untuk dapat menuangkan ide-ide kreatifnya ke dalam bentuk tulisan. Seorang pembimbing tugas akhir sebaiknya dapat meyakinkan mahasiswanya bahwa dia dapat menulis dengan baik asalkan mau kerja keras dan rajin, frekwentif, maka tugas akhir bukanlah sesuatu yang mustahil.

Dosen pembimbing sebaiknya merupakan orang yang menguasai bidang yang sesuai dengan topik tugas akhir mahasiswa, agar proses pembimbingan dapat berjalan secara optimal. Selain pembimbingan, mahasiswa juga membutuhkan dosen penguji yang akan menguji karya ilmiah mahasiswa dan apabila masih terdapat kekurangan, maka dapat disempurnakan lagi pada tahap revisi. (Septiana, Irfan, \& Atmadja, 2016)

Menurut Kinansih dalam (Achroza, 2013), dosen pembimbing mahasiswa adalah staf pengajar tetap suatu perguruan tinggi yang paling tepat untuk menjadi sumber bantuan nasehat akademik agar para mahasiswa dapat menyelesaikan 
tugasnya sebagai mahasiswa. Bantuan yang diberikan oleh dosen pembimbing akademik kepada individu-individu mahasiswa dimaksudkan agar mahasiswa dapat mengembangkan pandangan, mengambil keputusan dan menanggulangi konsekuensinya sendiri. Bimbingan yang diberikan oleh setiap dosen pembimbing skripsi/tugas akhir, kepada mahasiswa yang sedang menyusun skripsi/tugas akhir.

Sedangkan Menurut Rahardjo (Achroza, 2013), pembimbing skripsi/tugas akhir untuk setiap mahasiswa terdiri 2 orang dosen. Dosen sebagai pembimbing tugas akhir mahasiswa bertugas dan bertanggung jawab untuk: membimbing penyusunan rencana (proposal) penelitian/tugas akhir, memeriksa konsep, kerangka dan arah serta sasaran rencana penelitian, memonitor pelaksanaan penelitian, membimbing penyusunan skripsi/tugas akhir, memeriksa draf skripsi/tugas akhir.

Atas dasar penjelasan dari para ahli diatas maka penulis dapat mengambil kesimpulan bahwa dosen pembing adalah dosen yang mendampingi mahasiswa dalam menyusun karya ilmiahnya dari mulai penyusunan proposal hingga membuat laporan, dan juga orang yang mampu mengarahkan dan mengoptimalkan segala potensi diri yang dimiliki mahasiswa untuk menghasilkan sebuah karya ilmiah yang baik.

\section{Tugas Akhir}

Tugas akhir merupakan suatu karya ilmiah yang disusun mahasiswa untuk menyelesaikan studinya melalui proses berpikir ilmiah, kreatif, integratif, dan sesuai dengan disiplin ilmunya yang disusun untuk memenuhi persyaratan kebulatan studi dalam program dan jenjang pendidikan yang ada di lingkungan tempat study. Tugas akhir disusun dengan tujuan memberi kesempatan kepada mahasiswa agar dapat memformulasikan ide, konsep, pola berpikir, dan kreativitasnya yang dikemas secara terpadu dan komprehensif, dan dapat mengkomunikasikan dalam format yang lazim digunakan di kalangan masyarakat ilmiah

Slamet dalam (Gunawati, Hartati, \& Listiara, 2016), Masalah-masalah yang umum dihadapi oleh mahasiswa dalam menyusun skripsi adalah, banyaknya mahasiswa yang tidak mempunyai kemampuan dalam tulis menulis, adanya kemampuan akademis yang kurang memadai, serta kurang adanya ketertarikan mahasiswa pada penelitian.

Constantianus \& Suteja (2015) menyatakan bahwa dalam pembuatan Tugas Akhir, mahasiswa/i dipercaya untuk memilih serta mengusahakan sebuah topik tertentu yang sekiranya memiliki tingkat kesulitan yang sesuai dengan apa yang telah dia pelajari. Kelak hasil akhir dari pembuatan Tugas Akhir ini akan dipertanggungjawabkan dalam bentuk Ujian Sidang Tugas Akhir yang merupakan persyaratan utama untuk kelulusan serta pemberian gelar bagi mahasiswa/i tersebut. 
Sedangkan menurut (Machmud, 2016) dalam bukunya menyatakan bahwa Tugas Akhir merupakan salah satu jenis karya ilmiah yang disusun oleh mahasiswa dibawah bimbingan Dosen Pembimbing sehingga memenuhi kaidah dan standar kualitas sesuai dengan keilmuannya. Penulisan laporan Tugas Akhir harus mengikuti kaidah dan petunjuk teknis penulisan, baik yang diterbitkan oleh program studi masing-masing ataupun literatur yang membahas tentang penulisan karya ilmiah (tugas akhir).

\section{METODE PENELITIAN}

Dilihat dari permasalahan yang telah digambarkan pada pendahuluan, maka penelitian ini dapat digolongkan pada penelitian berjenis asosiatif yaitu gambaran informasi lengkap tentang hubungan antar variabel satu dengan gejala lain (X1 berhubungan interaktif dengan dengan X2 dan Y) Sugiono dalam (Damanik, 2018). Penelitian ini memiliki jenis hubungan yang linier karena pada dasarnya hendak melihat hubungan antara variable bebas yaitu minat baca dan peran dosen pembimbing.

Tempat penelitian ini dilaksanakan di Amik Tunas Bangsa Pematangsiantar dengan sasaran penelitian adalah mahasiswa yang sedang mengerjakan Tugas Akhir. Objek penelitian ini adalah: "perngaruh minat baca, dan peran dosen pembimbing terhadap keberhasilan penulisan tugas akhir".

Pengumpulan data primer dilakukan terhadap 369 orang dari seluruh populasi yang ada yaitu seluruh mahasiswa yang sedang melakukan pengerjaan tugas akhir dan dari populasi tersebut diperoleh sampel sebanyak 78 orang dengan perhitungan menggunakan rumus Slovin.

Pengumpulan data dalam penelitian ini penulis lakukan dengan berbagai cara yaitu: observasi dilapangan dengan melakukan pengamatan langsung ke para mahasiswa yang sedang melakukan penelitian tugas akhir dan juga prilaku dosen yang membimbing dalam membantu penyelesaian tugas akhir mahasiswa, wawancara yaitu dengan membuat pertanyaan-pertanyaan kecil tentang apa yang diharapkan dan yang tidak diharapkan dalam menunjang keberhasilan penulisan tugas akhir dan kuisioner, yaitu teknik pengumpulan data dengan membagikan kertas yang berisi daftar pertanyaan kepada responden (mahasiswa) AMIK Tunas Bangsa Pematangsiantar.

\section{Pengujian Hipotesis}

Dalam penelitian ini untuk menguji hipotesis penelitian menggunakan analisis regresi linier berganda yaitu melihat pengaruh variabel independent (variabel bebas) terhadap variabel dependent (variabel terikat), dengan menggunakan persamaan matematis yaitu analisis regresi linier berganda dengan rumus:

$$
Y=a+b 1 X 1+b 2 X 2+E
$$


Keterangan:

$\mathrm{Y}=$ Keberhasilan Tugas Akhir

A $=$ Konstanta

$\mathrm{b} 1=$ Koefesien regresi variabel $\mathrm{x}_{1}$

$\mathrm{b}_{2}=$ Koefesien regresi variabel $\mathrm{x}_{2}$

$\mathrm{X}_{1}=$ Minat Baca

$\mathrm{X}_{2}=$ Dosen Pembimbing

Analisis regresi linier berganda meliputi uji Koefisien Determinasi $\left(R^{2}\right)$ bertujuan untuk melihat sumbangan efektif variabel X1; X2; dalam menjelaskan variabel Y, uji $F$ bertujuan melihat pengaruh secara simultan variabel $X 1$; $X 2$ terhadap variabel $Y$ dan uji t untuk melihat pengaruh secara parsial masing-masing variabel $\mathrm{X} 1 ; \mathrm{X} 2$ terhadap variabel $\mathrm{Y}$, dan lebih lengkapnya dapat dilihat penjelasan berikut ini:

\section{HASIL DAN PEMBAHASAN}

\section{Uji Normalitas}

Untuk melihat apakah data yang digunakan dalam penelitian telah terdistribusi normal dapat dilihat dengan uji non parametrik satu sample Kolmogorov-Smirnov dalam hasil pengujian regresi. Uji ini bertujuan untuk meyakinkan apakah nilai residual dapat terdistribusi dengan normal dan independen. Hasil uji normalitas pada data penelitian ini ditunjukkan pada Tabel 1 di bawah.

Tabel 1. Uji Normalitas

One-Sample Kolmogorov-Smirnov Test

\begin{tabular}{|l|r|}
\hline & \multicolumn{2}{|c|}{ Unstandardized Residual } \\
\hline N & 78 \\
Asymp. Sig. (2-tailed) &, $200^{\circ}$ \\
\hline
\end{tabular}

a. Test distribution is Normal.

Pada Tabel 1 menunjukkan bahwa nilai Asymp. Sig (2-tailed) sebesar 0,200. Karena Asymp. Sig.(2-tailed) menunjukkan nilai sebesar 0,200 yang berarti lebih besar dari 0,05, maka dapat diinterpretasikan bahwa nilai residual dari model dapat dinyatakan telah berdistribusi normal.

\section{Pengaruh Minat Baca Terhadap Keberhasilan Tugas Akhir Di AMIK Tunas Bangsa Pematangsiantar.}

Untuk mengetahui secara partial pengaruh minat baca terhadap keberhasilan tugas akhir mahasiswa di AMIK Tunas Bangsa Pematangsiantar dapat dilihat pada Tabel 2 berikut ini. 


\begin{tabular}{|c|c|c|c|c|c|c|}
\hline \multicolumn{7}{|c|}{$\begin{array}{c}\text { Tabel 2. Hasil Olah Data Pengaruh Minat Baca Terhadap } \\
\text { Keberhasilan Tugas Akhir } \\
\text { Coefficients }^{a}\end{array}$} \\
\hline & \multirow[b]{2}{*}{ Model } & \multicolumn{2}{|c|}{$\begin{array}{l}\text { Unstandardized } \\
\text { Coefficients }\end{array}$} & \multirow{2}{*}{$\begin{array}{c}\begin{array}{c}\text { Standardize } \\
d \\
\text { Coefficients }\end{array} \\
\text { Beta }\end{array}$} & \multirow[b]{2}{*}{$\mathrm{t}$} & \multirow[b]{2}{*}{ Sig. } \\
\hline & & B & $\begin{array}{l}\text { Std. } \\
\text { Error }\end{array}$ & & & \\
\hline \multirow[t]{3}{*}{1} & (Constant) & $\begin{array}{c}23,52 \\
3\end{array}$ & 3,626 & & 6,488 & ,000 \\
\hline & Minat_Baca &, 243 & ,077 & ,350 & 3,167 & ,019 \\
\hline & $\begin{array}{c}\text { Dosen_Pembim } \\
\text { bing }\end{array}$ & ,270 & ,092 & ,323 & 2,915 & 05 \\
\hline
\end{tabular}

Dari Tabel 2 di atas diketahui bahwa nilai thitung $>\operatorname{ttabel}(3,167>1,991)$ maka diputuskan koefisien regresi signifikan atau $\mathrm{HO}$ ditolak dan menerima hipotesis dalam penelitian ini yaitu variabel minat baca secara partial berpengaruh positif dan signifikan terhadap keberhasilan tugas akhir mahasiswa di AMIK Tunas Bangsa Pematangsiantar.

\section{Pengaruh Dosen Pembimbing Terhadap Keberhasilan Tugas Akhir Di AMIK Tunas Bangsa} Pematangsiantar

Untuk mengetahui secara partial pengaruh Dosen Pembimbing terhadap keberhasilan Tugas Akhir mahasiswa Di AMIK Tunas Bangsa Pematangsiantar dapat dilihat pada Tabel 2 di atas diketahui bahwa nilai thitung $>$ ttabel $(2,915>1,991)$ maka diputuskan koefisien regresi signifikan atau $\mathrm{HO}$ ditolak dan menerima hipotesis dalam penelitian ini yaitu variabel Dosen Pembimbing secara partial berpengaruh positif dan signifikan terhadap keberhasilan Tugas Akhir di AMIK Tunas Bangsa Pematangsiantar.

Pengaruh Minat Baca Dan Dosen Pembimbing Terhadap Keberhasilan Tugas Akhir Di AMIK Tunas Bangsa Pematangsiantar

Tabel 3. ANOVAa

\begin{tabular}{|c|c|c|c|c|c|c|}
\hline & Model & $\begin{array}{l}\text { Sum of } \\
\text { Squares }\end{array}$ & Df & $\begin{array}{l}\text { Mean } \\
\text { Square }\end{array}$ & $F$ & Sig. \\
\hline \multirow[t]{3}{*}{1} & Regression & 82,266 & 2 & 41,133 & 20,094 &, $000^{b}$ \\
\hline & Residual & 153,528 & 75 & 2,047 & & \\
\hline & Total & 235,795 & 77 & & & \\
\hline
\end{tabular}


a. Dependent Variable: Keberhasilan-TA

b. Predictors: (Constant), Dosen_Pembimbing, Minat_Baca

Dari Tabel 3 di atas, untuk membuktikan kebenaran hipotesis penelitian atau apakah nilai korelasi itu dapat digeneralisasikan, maka harus diuji signifikansinya dengan uji-F, dan dari pengolahan data diketahui nilai Fhitung sebesar 20,094. Nilai F-hitung ini selanjutnya diinterpretasikan dengan nilai Ftabel dan dengan tingkat kpercayaan 95\% $(\alpha=0,05)$, dengan dk pembilang $=k$ dan dk penyebut $=(n-k-1)$ $=78-2-1=78$, maka nilai Ftabel $=3,12$. Jadi dari hasil perhitungan uji signifikan, dapat dilihat bahwa nilai Fhitung > Ftabel yaitu 20,094 >3,12, jadi hipotesis penelitian secara simultan dapat dibuktikan yaitu terdapat pengaruh positif dan signifikan antara minat baca dan dosen pembimbing terhadap keberhasilan Tugas Akhir mahasiswa di AMIK Tunas Bangsa Pematangsiantar.

\section{Analisis Regresi Linier Berganda}

Analisis regresi linier berganda ini digunakan untuk mengestimasi pengaruh minat baca dan peran Dosen Pembimbing terhadap keberhasilan Tugas Akhir di AMIK Tunas Bangsa Pematangsiantar. Berdasarkan hasil pengolahan data diperoleh hasil sebagai berikut:

Tabel 4. Analisis Regresi Linier Berganda Coefficients $^{a}$

\begin{tabular}{|l|r|r|r|r|r|}
\hline \multirow{2}{*}{ Model } & \multicolumn{2}{|c|}{$\begin{array}{c}\text { Unstandardized } \\
\text { Coefficients }\end{array}$} & \multicolumn{1}{c|}{$\begin{array}{c}\text { Standardized } \\
\text { Coefficients }\end{array}$} & & \\
\cline { 2 - 4 } & \multicolumn{1}{|c|}{$\mathrm{B}$} & Std. Error & \multicolumn{1}{|c|}{ Beta } & \multicolumn{1}{c|}{ t } & \multicolumn{1}{c|}{ Sig. } \\
\hline 1 (Constant) & 23,523 & 3,626 & & 6,488 &, 000 \\
Minat_Baca &, 243 &, 077 &, 350 & 3,167 &, 002 \\
Dosen_Pembimbing &, 270 &, 092 &, 323 & 2,915 &, 005 \\
\hline
\end{tabular}

a. Dependent Variable: Keberhasilan-TA

Berdasarkan pada Tabel 4, di atas, persamaan regresi linier berganda adalah sebagai berikut:

$$
Y=14,726+0,243 X 1+0,270 X 2+\varepsilon
$$

Dengan persamaan regresi linier berganda tersebut dapat dijelaskan bahwa:

1. Nilai konstanta adalah sebesar 14,726 , hal ini menyatakan bahwa jika minat baca dan Dosen Pembimbing diabaikan maka nilai motivasi belajar mahasiswa sebesar 14,726.

2. Koefisien regresi untuk variabel minat baca sebesar 0,243 , hal ini menunjukkan bahwa setiap kenaikkan 1\% faktor minat baca maka keberhasilan Tugas Akhir akan meningkat sebesar $2,43 \%$.

3. Koefisien regresi untuk variabel Dosen Pembimbing sebesar 0,270, hal menunjukkan bahwa setiap kenaikkan 1\% faktor Dosen Pembimbing maka keberhasilan Tugas Akhir mahasiswa akan meningkat sebesar 2,70 \%. 


\section{KESIMPULAN DAN SARAN}

\section{Kesimpulan}

Berdasarkan hasil penelitian, maka dapat disimpulkan hal-hal sebagai berikut:

1. Minat baca secara partial berpengaruh positif dan signifikan terhadap keberhasilan Tugas Akhir mahasiswa di AMIK Tunas Bangsa Pematangsiantar dapat dilihat dari nilai thitung $>$ ttabel $(3,167>1,991)$.

2. Peran Dosen Pembimbing secara partial berpengaruh positif dan signifikan terhadap keberhasilan Tugas Akhir mahasiswadi AMIK Tunas Bangsa Pematangsiantar dapat dilihat dari nilai thitung $>$ ttabel $(2,915>1,991)$.

3. Minat baca dan peran Dosen Pembimbing secara simultan berpengaruh positif dan signifikan terhadap keberhasilan Tugas Akhir mahasiswa di AMIK Tunas Bangsa Pematangsiantar, dapat dilihat dari nilai Fhitung > Ftabel yaitu $(20,094>$ $3,12)$

\section{Saran}

Berdasarkan kesimpulan yang telah diuraikan, maka dapat disampaikan beberapa saran yaitu untuk lebih dapat menghasilkan karya ilmiah berupa Tugas Akhir yang akan dihasilkan mahasiswa, maka disarankan untuk seluruh mahasiswa agar sejak dini ditanamkan budaya gemar membaca supaya nantinya dapat menghasilkan karya-karya ilmiah yang lebih berkwalitas.

Kepada Dosen Pembimbing yang ditugaskan membimbing mahasiswa dalam menyelesaikan Tugas Akhir agar sungguh-sungguh mendampingi mahasiswa bimbingannya dam memberikan ide-ide kreatifnya agar kwalitas Tugas Akhir yang dihasilkan mahasiswa dapat ditingkatkan dari waktu ke waktu. Kepada seluruh Dosen di lingkup AMIK Tunas Bangsa Pematangsiantar juga disarankan agar meningkatkan level keilmuannya dengan banyak membaca dan menulis karya ilmiah.

Bagi peneliti selanjutnya yang ingin melakukan penelitian terkait, diharapkan untuk mempertimbangkan dalam menambah teknik analisis data menggunakan analisi path, tambahan variable lainnya,sampel dan populasi yang diperluas.

\section{DAFTAR PUSTAKA}

Achroza, F. H. 2013. Hubungan Antara Komunikasi Interpersonal Dosen Pembimbing Mahasiswa dan Problem Focused Coping dengan Stres Dalam Menyusun Skripsi Pada Mahasiswa FKIP Bimbingan dan Konseling Universitas Muria Kudus. Skripsi. Kudus: Fakultas Psikologi Universitas Muria Kudus (tidak diterbitkan).

Arikunto, S. 2010. Prosedur penelitian: Suatu Pendekatan Praktik. (Edisi Revisi). Jakarta: Rineka Cipta 
Arikunto, Suharsimi. (2006). Manajemen Penelitian. Jakarta: Rineka Cipta. Azwar, S. (2000). Reliabilitas dan Validitas. Yogyakarta: Pustaka Pelajar Offset.

Constantianus, F., \& Suteja, R. B. (2015). Analisa dan Desain Sistem Bimbingan Tugas Akhir Berbasis Web dengan Studi Kasus Fakultas Teknologi Informasi. Jurnal Informatika.

Damanik, B. E. (2018). Pengaruh Motivasi Dan Pengembangan Diri Terhadap Prestasi Kerja Dosen. Jurnal Ekonomi Dan Bisnis (EK \& BI) , 20-28.

Failasuf, Ashef Fiqo. (2013). Pengaruh Perhatian Orang Tua Siswa, Kebiasaan Belajar dan Nilai UAN Terhadap Prestasi Mata Pelajaran Teori Pemesinan Kelas 1 SMK Negeri 3 Yogyakarta dan SMK Muhamadiyah 3 Yogyakarta Tahun 2012/2013. Tugas Akhir Skripsi. UNY.

Gunawati, R., Hartati, S., \& Listiara, A. (2016, Desember). Hubungan Antara Efektivitas Komunikasi Mahasiswa- Dosen Pemimbing Utama Skripsi Dengan Stres Dalam Menyusun Skripsi Pada Mahasiswa Program Studi Psikologi Fakultas Kedokteran Universitas Diponegoro. Jurnal Psikologi Universitas Diponegoro, 3.

Herdianto, D. (2011). Studi Tentang Minat Baca Mahasiswa. Majalah IImiah Pembelajaran, Volume 7 Mei(Nomor 1 ).

Indarwati, Feri. (2011). Pengaruh Pemanfaatan Unit Produksi Sekolah dan Kebiasaan Belajar Siswa Terhadap Prestasi Belajar Kewirausahaan Siswa Kelas II Akuntansi SMK Negeri 1 Yogyakarta Tahun Ajaran 2009/2010.Tugas Akhir Skripsi. UNY.

Machmud, M. (2016). Tuntunan Penulisan Tugas Akhir Berdasarkan Prinsip Dasar Penelitian IImiah. Malang: Penerbit Selaras.

Marzuki. 2012. Metodologi Riset. Yogyakarta: Fakultas Ekonomi Universitas Islam Indonesia

Putra, R., Suprayogi, A., \& Kahar, S. (2013, Oktober). Aplikasi SIG Untuk Penentuan Daerah Quick Count Pemilihan Kepada Daerah. Jurnal Geodesi Undip.

Septiana, I., Irfan, M., \& Atmadja, A. R. (2016). Sistem Pendukung Keputusan Penentu Dosen Penguji Dan Pembimbing Tugas Akhir Menggunakan Fuzzy Multiple Attribute Decision. JOIN, No. 1.

Siagian, R. E. (2012). Pengaruh Minat Dan Kebiasaan Belajar Siawa Terhadap Prestasi Belajar Matematika. Jurnal Formatif 2(2): 122-131.

Sugiyono. 2005. Statistika Untuk Penelitian. Bandung: Alfabeta

Sugiyono. 2012. Metode Penelitian Pendidikan, Bandung: Alfabeta

Triton, 2006. Riset Statistik Parametrik, Penerbit Andi, Yogyakarta. 